\title{
PULAU SENTINEL DALAM HUKUM LAUT INTERNASIONAL
}

\author{
Tomy Michael \\ Universitas Swadaya Gunung Jati, Cirebon, Indoensia
}

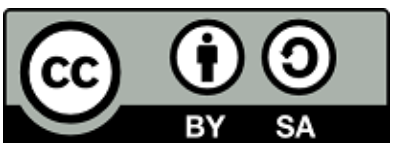

DOI: http://dx.doi.org/10.33603/hermeneutika.v3i2

Diterima: 24 Mei 2020; Direvisi: 19 Juli 2020; Dipublikasikan: Agustus 2020

\begin{abstract}
Abstrak: Tujuan penelitian untuk mengetahui bagaimana status Pulau Sentinel dalam hukum lau internasional dan menggunakan metode penelitia pendekatan. Pulau Sentinel sebagai pulau yang memiliki kompleksitas permasalahan hukum seperti adanya izin dari Pemerintah India untuk mengunjunginya dan laranagan untuk mengunjungi di sekitarnya. Penelitian ini dilakukan dengan metode penelitian metode pendekatan empiris yuridis, yaitu dimana penulis mencari, menggali, dan menemukan fakta-fakta serta kenyataan yang ada di dalam masyarakat dengan melihat situasi dan kondisi yang terjadi. Di dalam perspektif UNCLOS 1982, pulau buatan tidak diperinci secara detail karena pulau masih menganut pemahaman akan ekonomis padahal pulau buatan untuk saat ini adalah suatu kebutuhan di suatu negara. Keleluasaan ini secara tertulis diatur dalam Pasal 87 UNCLOS 1982 dimana laut lepas terbuka untuk semua Negara, baik Negara pantai atau tidak berpantai. Sebagai kesimpulannya Pulau Sentinel termasuk pulau alami yang tidak berpenghuni. Pemberian pulau alami dikarenakan pulau ini ada dan tidak merupakan pulau buatan dalam perspektif UNCLOS 1982. Sementara pemberian nama pulau tidak berpenghuninya karena adanya larangan dari Pemerintah India dengan argumen tidak menghuni untuk menjaga keberlangsungan hidup dari suku asli tersebut.
\end{abstract}

Kata kunci: Pulau Sentinel, pulau buatan, subjek hukum

\footnotetext{
${ }^{1}$ Tomy Michael

Email: tomymichael@gmail.com
} 


\section{PENDAHULUAN}

Perkembangan hukum internasional saat ini khususnya hukum laut selalu mengikuti tren berbagai negara dunia. ${ }^{2}$ Hukum internasional sebagai bagian perkembangan dunia selalu menjadi bagian dalam norma hukum di dalam suatu negara. Fakta hukum Pulau Sentinel ${ }^{3}$

2 Tren dalam artikel ini, penulis artikan sebagai kebiasaan berupa aturan jus cogens. Jus cogens sendiri bukanlah aturan baru yang berlaku secara universal namun ia telah berada dalam suatu lingkup daerah tertentu, lebih lanjut dalam Malcolm N. Shaw QC, International Law Sixth Edition, Cambridge University Press, The Edinburgh Building, Cambridge CB2 8RU, UK, 2008, hlm. 126.

3 The sea around the island divide it into two groups, Andaman and Nicobar. They stretch over 500 miles of water in the BAY OF BENGAL situated between the 6th and 14th parallel of North latitude and between 92 and 94 degree of East longitude. Andaman and Nicobar Islands were constituted in to Union Territory in November, 1956. They are also known as BAY ISLAND. The Bay Island with geographical area of $8298 \mathrm{sq} \mathrm{km}$ consists of 572 Islands spread in Bay of Bengal at a distance of $1,200 \mathrm{~km}$ from the East Coast of mainland India. These Islands are surrounded by the mainland India in the North and West by Myanmar, while in the East lies Thailand and Malaysia.Andaman and Nicobar Island lie along an arch in long chain, approx.North-South over a distance nearly 800 kms.. Andaman consists of 239 small and large island. The total area closely connected large islands, North, Middle and South Andaman which with other two islands Baratang and Rut-Land almost form one landmass known as the Great Andaman's. The Nicobar having 19 islands of which 13 are inhabited by near about 12,000 aboriginal tribals. Half of the total area is covered by the Great Nicobar Port Blair, the capital of the Andaman and Nicobar Islands. Here, near about 7170.09 sq. $\mathrm{Km}$ area are forested in which 2928.76 sq. $\mathrm{km}$ are reserved and $4241.93 \mathrm{sq} \mathrm{km}$. are protected forest. Around 3000 species of plant, timber species 200 and 36 commercial plants are discovered on this land. The $\mathrm{A} \& \mathrm{~N}$ islands are home to six aboriginal tribes. Great Andamanese, Jarawa, Onge, and Sentinelese are of Negrito origin, whose settlements are restricted to the Andaman group of islands viz. Strait Island, Jarawa reserve forest, Little Andaman, and Sentinel Island. Negritos have a dark complexion and are short in stature with peppercorn hair. Nicobarese and Shompens are of Mongol- oid origin and reside in the Nicobar group of islands viz. Car Nicobar, Chowra, Nancowry, Trinket, Katchal, Kam- orta, and Great Nicobar islands. The islands are also inhabited by settlers who are either ex-convicts from the cellular jail, migrants from the main- land, or refugees from Bangladesh, Myanmar, and SriLanka. They have settled in most of the islands as insular groups based on their language, occupation, region, and religion. The ethnic communities and the settlers heavily depend on the natural resources for their subsistence as well as for cash income similar to other communities of mainland or in other Southeast Asian countries. This island is a residence place of of five primitive tribes, viz. Jarawas, Sentinelese, Onges, Nicobarese, Shompens. The Andaman Islands are home to four 'Negrito' tribes - the Great Andamanese, Onge, Jarawa and Sentinelese. The 'Negrito' tribes are 60,000 years old and arrived from Africa. They all are nomadic huntergatherers, hunting wild pig and monitor lizard, and catching fish with bows and arrows. They also collect honey, roots berries from the forest.The Nicobar Islands are home to two 'Mongoloid' tribes - the Shompen and Nicobarese.The 'Mongoloid' tribes probably came to the islands from the MalayBurma coast several thousand years ago.The number of population of Great Andamanese are 43 . The tribe that has suffered most from contact with outsiders: $99 \%$ have been wiped out since the British first colonized the islands. The main threat to their existence comes from the highway running through their territory: the Indian government was ordered to close this by the Supreme Court in 2002, but it has ignored the order. The estimated population of Sentinelese is 50-250 in number. The most isolated of all the tribes, lived in the Andaman Islands for up to 55,000 years they have no peaceful contact with outsiders, and fire warning arrows at those who approach. Their home, Sentinel Island, appears to have been relatively unaffected by the tsunami, and some Sentinelese have been sighted since the disaster. They are completely self-sufficient hunter-gatherers. Shompens are 380 in terms of population. A relatively isolated tribe of Great Nicobar Island, the Shompen are huntergatherers who have some, limited, contact with outsiders. Overflights of their territory suggest their forest has been little damaged, raising hopes that the tribe has survived more or less intact. Nicobareses are well populated tribes near about 30,000 in numbers. Unlike the other tribes, the Nicobarese are largely horticulturalists. Most have converted to Christianity, and are much more assimilated than the other Andaman and Nicobar tribes, but still maintain their own distinct culture. The Nicobarese have also suffered much more from the tsunami, 
untuk dibahas adalah pembatasan yang diberlakukan oleh Pemerintah India. $^{4}$

Jyoti Dwivedi, The Dependence of Andaman and Nicobar Island Tribal Communities on Herbal Remedies, IOSR Journal of Environmental Science, Toxicology and Food Technology (IOSR-JESTFT) e-ISSN: 2319-2402,p- ISSN: 2319-2399.Volume 9, Issue 11 Ver. II (Nov. 2015), PP 45-53.

4 The Government has promulgated various laws/regulations from time to time to ensure that the rights and well being of the Sentinelese are safeguarded. These are being strictly implemented and enforced by the UT Administration. These Laws/Regulation include i) A \&N Islands (PAT) Regulation 1956, ii) Scheduled Castes and the Scheduled Tribes (Prevention of Atrocities) Act, 1989, iii) Restrictions under Foreigner (Restricted Area) Orders, 1963, iv) Visa Manual Conditions/Passport Act 1920, and v) Indian Forest Act, 1927 and Wildlife (Protection) Act, 1972. Besides, some major steps taken to ensure the protection of Sentinelese are:

(a) The entire North Sentinel Island along with 5 $\mathrm{km}$ coastal sea from high water mark is notified as tribal reserve.

(b) The Sentinelese are still in isolation practicing primordial hunting and gathering way of life. The Government respects their way of life style, therefore, has adopted an 'eyes-on and hands-off' practice to protect and safeguard the Sentinelese tribe.

(c) A protocol of circumnavigation of the North Sentinel Island has been notified. The ships and aircrafts of Coast Guard and boats of Marine Police make sorties around North Sentinel to keep surveillance.

Apart from the land territory the coastal sea up to fixed extent of $1 \mathrm{Km}$ to $5 \mathrm{Km}$ abutting the tribal territory has also been notified as tribal reserve so that marine resources like fish, turtle etc are available exclusively for the Particularly Vulnerable Tribal Groups (PVTGS). The vehicular traffic on Andaman Trunk Road passing through Jarawa reserve is regulated by convoy system. Buffer Zone notified in 2013, around the Jarawa Tribal Reserve $(5 \mathrm{~km}$ landward side and $1 \mathrm{~km}$ seaward side), prohibits all commercial/tourism activity in the Buffer Zone. Joint patrolling by Police, Forest \& Andaman Adim Janjati Vikas Samiti (AAJVS) is carried out around Jarawa area to prevent contact of poachers and unscrupulous non-tribal elements with Jarawa tribe. A Special Police Team (01 SI and $10 \mathrm{PCs}$ ) for patrolling at Tirrur, adjacent to the Jarawa Tribal Reserve, has also been deployed. The ships and aircrafts of Coast Guard and boats of Marine Police make
Dalam kajian hukum laut, keberadaan Pulau Sentinel tidak diatur secara rinci. Hukum laut yang menggunakan dasar hukum United Nations Convention On The Law Of The Sea 1982 (UNCLOS 1982) dimana telah diratifikasi dengan UndangUndang Republik Indonesia Nomor 17 Tahun 1985 tentang Pengesahan United Nations Convention On The Law Of The Sea (Konvensi Perserikatan BangsaBangsa Tentang Hukum Laut) (UU No. 17-1985). ${ }^{5}$

\section{Mengacu pada Pasal 6 UNCLOS} 1982 bahwa dalam hal pulau yang terletak pada atol atau pulau yang mempunyai karang-karang disekitarnya, maka garis pangkal untuk mengukur lebar laut teritorial adalah garis air rendah pada sisi karang ke arah laut sebagaimana ditunjukkan oleh tanda yang jelas untuk itu pada peta yang diakui resmi oleh Negara pantai yang bersangkutan. ${ }^{6}$ Pasal ini

sorties around North Sentinel to keep surveillance. The details of population of the Sentinelese and Jarawa Tribes are as under:

\begin{tabular}{|l|l|l|}
\hline S.No & Name of the tribe & Population \\
\hline 1. & Jarawa & 514 (till date) \\
\hline 2. & Sentinelese & $\begin{array}{l}50 \text { estimated as per } \\
2011 \text { census }\end{array}$ \\
\hline
\end{tabular}

The number of confrontational incidents occurred during the last ten years with the Sentinelese and the Jarawas tribe are given as under:

(i) Sentinelese 01(one)

(ii) Jarawas 19 (Nineteen)

Press Information Bureau Government of India Ministry of Home Affairs, 5 Feb 2019, https://pib.gov.in/Pressreleaseshare.aspx?PRID=15 62728, diakses 6 Februari 2020.

5 Dalam penelitian ini, penulis memaknai Pulau Sentinel sebagai pulau tidak berpenghuni dengan argumen adanya larangan dari Pemerintah India.

6 Perbandingan dengan Indonesia memiliki laut yang sangat luas sekaligus mengandung sumber daya yang tak terkira. Hal ini menjadi semacam magnet yang menarik banyak pihak untuk sekedar datang mengail ikan atau bahkan keinginan menguasai. Bernard Kent Sondakh, 'PERAN TNI 
memunculkan permasalahan hukum bahwa tidak seluruh pulau bisa dijadikan sebagai tolak ukur menjadi garis pangkal. Pulau "diwajibkan" untuk memiliki karangkarang padahal karang-karang tersebut telah muncul secara alamiah. Artinya suatu pulau hampir memiliki karang dan kepemilikan karang tersebut dapat dibatalkan secara pihak oleh negara pantai apabila tidak memiliki keuntungan.

Penulis membandingkan 4 (empat) penelitian yaitu vaccination and importation of dogs and cats are prohibited in the Galapagos, resulting in a uniquely isolated population. The purpose of this study was to determine the prevalence of infectious diseases of dogs and cats that impact their health, could spill over to native wildlife, or sentinel diseases of concern to humans. Hypothesis: The isolation of dogs and cats in the Galapagos protects them from diseases common in mainland populations. Animals: Ninety-five dogs and 52 cats presented during a neutering campaign. ${ }^{7}$ Dalam penelitian pertama terkait penggunaan Pulau Galapagos dimana didalamnya ada anjing dan kucing. Pembatasan untuk melindungi kedua hewan dari penyakit berbahaya. Penelitian kedua yaitu global warming and rising sea levels are increasingly causing major problems for low lying Pacific and Indian Ocean island nations. The Republic of Kiribati in the South Pacific is currently in a dire situation, and increasing levels of

AL DALAM PENGAMANAN DAN
PEMBERDAYAAN PULAU TERLUAR RI', Jurnal Hukum \& Pembangunan, 2017 $<$ https://doi.org/10.21143/jhp.vol33.no1.1368>.

7 J. K. Levy and others, 'Infectious Diseases of Dogs and Cats on Isabela Island, Galapagos', Journal of Veterinary Internal Medicine, 2008 $<$ https://doi.org/10.1111/j.1939-

1676.2007.0034.x>. international aid will be required to maintain the population at its current standard of living. This paper describes a sustainable artificial island, designed for the inhabitants of South Tarawa, the capital island of the Republic of Kiribati. Design targets were to improve infrastructure, services and quality of life for the inhabitants, to increase island sustainability and to minimise construction costs. Dalam penelitian kedua terkait peningkatan populasi di salah satu pulau di Republik Kiribati. ${ }^{8}$ Penelitian ketiga yaitu pembentukan Kawasan Konservasi Perairan Laut Kabupaten Sukabumi sekaligus pencadangan Kawasan Penyu Pantai Pangumbahan sebagai Kawasan Konservasi Pesisir dan Pulau-Pulau Kecil (KKP3K), secara langsung maupun tidak langsung sangat membutuhkan peran serta masyarakat sekitar dalam pengelolaannya. Pandangan (persepsi) masyarakat tentang kegiatan konservasi di lingkungan sekitar diharapkan dapat membantu peningkatan kegiatan pengelolaan di KKLD Kabupaten Sukabumi. ${ }^{9}$ Dalam penelitian ketiga terkait konservasi suatu pulau sehingga eksistensi pulau mauapun makhluk hidup didalamnya tetap ada. Penelitian keempat yaitu konflik Indonesia dengan Cina terkait sembilan garis di Laut Natuna Utara. Adanya perebutan gas dan batasan dari Indonesia dengan negara lainnya sehingga memiliki implikasi hukum atas

\footnotetext{
${ }^{8}$ Natasha Lister and Ema Muk-Pavic, 'Sustainable Artificial Island Concept for the Republic of Kiribati', Ocean Engineering, 2015 $<$ https://doi.org/10.1016/j.oceaneng.2015.01.013>.

9 Irma Minarti Harahap, Achmad Fahrudin, and Yusli Wardiatno, 'Pengelolaan Kolaboratif Kawasan Konservasi Penyu Pangumbahan Kabupaten Sukabumi (Collaborative Management of Sea Turtle Pangumbahan Marine Protected Area, Sukabumi District)', Jurnal Ilmu Pertanian Indonesia (JIPI), 2015.
} 
kepulauan tersebut. ${ }^{10}$ Dari latar belakang tersebut maka rumusan masalah yang muncul yaitu bagaimanakah Pulau Sentinel dalam hukum laut internasional?. ${ }^{11}$

\section{METODE PENELITIAN}

Penelitian ini dilakukan dengan pendekatan empiris yuridis, yaitu dimana penulis mencari, menggali, dan menemukan fakta-fakta serta kenyataan yang ada di dalam masyarakat dengan melihat situasi dan kondisi yang terjadi. Serta memadukan dan melakukan interpretasi akan UNCLOS 1982 dengan aturan-aturan dan norma hukum yang sesuai dengan permasalahan yang diangkat oleh penulis. ${ }^{12}$

\section{HASIL PENELITIAN}

\section{Memaknai Pulau Dalam Hukum Laut Internasional}

Definisi pulau mengacu Pasal 121 UNCLOS 1982 yaitu daerah daratan yang dibentuk secara alamiah yang dikelilingi oleh air dan yang ada di atas permukaan air pada air pasang; kecuali dalam hal sebagaimana ditentukan dalam ayat 3, laut teritorial, zona tambahan, zona ekonomi eksklusif dan landas kontinen suatu pulau ditetapkan sesuai dengan ketentuan konvensi ini yang berlaku bagi wilayah darat lainnya; batu karang yang tidak dapat

${ }^{10}$ Rizal Dwi Novianto, Dimas Agung Firmansyah, and Naufal Adi Pratama, 'PENYELESAIAN SENGKETA DI LAUT NATUNA UTARA', Jurnal Hukum Bisnis Bonum Commune, 2020 $<$ https://doi.org/10.30996/jhbbc.v3i1.3074>.

11 Tomy Michael, 'RIGHT TO HAVE RIGHTS', Mimbar Keadilan, 2017, 106 $<$ https://doi.org/10.30996/mk.v0i0.2203>.

12 Astra Yuli Satyarini Sukendar, Amanda Raissa, Tomy Michael, Pengurangan Pekerja Anak Perempuan Di Lingkungan Pondok Pesantren, Mizan: Jurnal Ilmu Hukum, Volume 8 Nomor 2, Desember 2019 ISSN : 2301-7295 e-ISSN : 26572494. mendukung kediaman manusia atau kehidupan ekonomi tersendiri tidak mempunyai zona ekonomi eksklusif atau landas kontinen. ${ }^{13}$ Sebetulnya definisi

${ }^{13}$ Pengertian konfigurasi umum kepulauan (general configuration of the archipelago) adalah sangat subjektif karena tidak ada batasan pengertian ini. Oleh sebab itu, adanya pendapat bahwa konfigurasi umum kepulauan ditentukan dari panjangnya garis pangkal tersebut yaitu maksimal 100 mil. Tetapi ada pendapat lain bahwa untuk mengetahui pengertian konfigurasi umum kepulauan perlu dilihat dari sejarah pembentukan konsep tersebut yaitu diawali dari hasil putusan sidang ICJ pada putusan sidang Anglo Norwegian Fisheries Case 1951 yang antara lain secara teknis tidak boleh menyimpang antara 15 - 20 derajat dari arah umum pantai (general direction of the coast), putusan ini memang untuk negara Pantai (coastal state) bukan untuk negara kepulauan, selain itu rumusan pasalnya memang berlainan tetapi konsep pembentukannya memang dari sidang ICJ tersebut. Permasalahan in memang sulit dicari titik temu karena subjektif untuk itu diperlukan pembahasan tersendiri untuk tiap kondisi geografi suatu daerah dengan argumentasi yang dapat dibenarkan dari segi teknis dan hukum., lebih lanjut "In this connection, the practice of States does not justify the formulation of any general rule of law. The attempts that have been made to subject groups of islands or coastal archipelagoes to conditions analogous to the limitations concerning bays (distance between the islands not exceeding twice the breadth of the territorial waters, or ten or twelve sea miles), have not got beyond the stage of proposals. Furthermore, apart from any question of limiting the lines to ten miles, it may be that several lines can be envisaged. In such cases the coastal State would seem to be in the best position to appraise the local conditions dictating the selection", FISHERIES CASE (United Kingdom v. Norway) International Court of Justice December 18, 1951 General List No. 5.

"For the purposes of this exercise, normal rather than claimed straight or archipelagic baselines have been used for the surrounding mainland and main island coastlines. This approach is consistent with past international judicial practice which has tended to ignore claimed straight baselines when determining the basepoints from which to construct equidistance lines", lebih lanjut dalam Beckman, R. C. and Schofield, C. H. (2014). Defining EEZ claims from islands: A potential South China Sea change. International Journal of Marine and Coastal Law, 29 (2), 193-243. 
pulau menurut UNCLOS tidak relevan lagi dengan definisi pulau saat ini karena pulau bisa dimunculkan dengan artifisial seperti di Dubai. Perhatikan pulau yang berhubungan dengan batu karang dimana batu karang selalu tampak di atas permukaan air laut pada waktu pasang, meskipun tidak mendukung kediaman manusia atau ekonomi tetapi sepanjang batu karang itu terletak di depan atau mengitari pantai dari pulau tersebut. Dengan demikian, batu karangtersebut dapat dijadikan sebagai titik dalam pengukuran garis pangkal. ${ }^{14}$ Pulau juga bisa diartikan sebagai pulau buatan yang sebetulnya adalah pulau timbul tenggelam namun adanya bangunan permanen diatasnya. Bandingkan dengan Pulau Pasir Kenjeran dan Pulau Lusi di Sidoarjo. ${ }^{15}$ Pulau dan negara kepulauan memiliki makna yang berbeda dalam konteks hukum laut karena suatu pulau belum tentu dimiliki oleh suatu negara dan negara pun belum tentu juga memiliki pulau yang sifatnya buatan. Pasal 46 UNCLOS 1982 menjelaskan bahwa negara kepulauan adalah negara yang seluruhnya terdiri dari satu atau lebih kepulauan dan dapat mencakup pulau-pulau lain; kepulauan dalam hal ini suatu gugusan pulau, termasuk bagian pulau, perairan diantaranya dan lain-lain wujud alamiah yang hubungannya satu sama lainnya dmeikian eratnya sehingga pulau-pulau, perairan dan wujud alamiah lainnya itu merupakan suatu kesatuan geografi, ekonomi dan politik yang hakiki, atau

${ }^{14}$ I Wayan Kartika, Hukum Laut Internasional Dan Hukum Laut Indonesia, Yrama Widya, Bandung, 2014, hlm. 131.

15 Yanelis Prasenja, 'Peran Masyarakat Dalam Pengelolaan Ekominawisata Pulau Lusi, Kabupaten Sidoarjo', Majalah Geografi Indonesia, 2018 $<$ https://doi.org/10.22146/mgi.28695>. yang secara historis dianggap sebagai demikian. ${ }^{16}$

Dalam hal ini Pulau Sentinel merupakan pulau yang ditempati oleh manusia namun tidak dapat dijadikan garis pangkal. Menurut hak dan kewajiban negara pantai bahwa wajib melakukan:

a. Membebani kewajiban negara pantai untuk menentukan jumlah tangkapan sumber daya alam hayati yang dapat diizinkan pada zona ekonomi eksklusifnya. Negara pantai juga diwajibkan untuk menjamin pemeliharaan sumber daya alam hayati pada zona ekonomi eksklusifnya berdasarkan atas bukti-bukti ilmiah yang andal dan tersedia dengan cara melakukan tindakan konservasi.

b. Negara pantai diwajibkan untuk menetapkan lebih dahulu kemampuannya untuk memanfaatkan hasil tangkapan atas sumber daya alam hayatinya sesuai volume yang diperbolehkan sehingga masih ada sisanya.

c. Negara pantai harus bekerja sama secara langsung dengan negara yang nelayannya menangkap ikan di area tersebut ataupun dengan organisasi internasional. ${ }^{17}$

16 Ganewati Wuryandari and Sandy Nur Ikfal Raharjo, 'Menegosiasikan Batas Wilayah Maritim Indonesia Dalam Bingkai Negara Kepulauan', Masyarakat Indonesia, 2016.

17 Garis dasar lurus menutup teluk dan muara sungai, dan garis dasar lurus ditarik di sepanjang pantai yang sangat menjorok ke dalam dan memotong atau dibatasi dengan pulau, akan menciptakan daerah perairan internal antara garis dasar lurus dan garis air rendah di sepanjang daratan atau pulau sekitar pantai, Mazen Adi, The Application Of The Law Of The Sea And The Convention On The Mediterranean Sea, United Nations-Nippon Foundation Fellow 2008 - 2009, Division For Ocean Affairs And The Law Of The Sea Office Of Legal Affairs, The United Nations New York, 2009, hlm. 15. 


\section{Esensi Pulau Sentinel Sebagai Pulau Yang Berdaulat \\ Pulau buatan dalam UNCLOS 1982} diatur sebagai bagian dari otoritas negara dalam mempertahankan kedaulatannya (bandingkan dengan pulau sebagai subjek hukum internasional). ${ }^{18}$ Di dalam hal ini pengaturan memberi kebebasan yang mana seluruh negara bisa memiliki laut lepas. Secara jelas dalam Pasal 87 UNCLOS 1982 yaitu

"Laut lepas terbuka untuk semua Negara, baik Negara pantai atau tidak berpantai. Kebebasan laut lepas, dilaksanakan berdasarkan syarat-syarat yang ditentukan dalam Konvensi ini dan ketentuan lain hukum internasional. Kebebasan laut lepas

Makna sebuah pulau adalah dalam wujud apapun dan dimanapun betapapun minimnya wilayahnya, mama pulau tersebut memiliki laut teritorialnya sendiri, sama seperti wilayah daratan lainnya.Formasi laut yang bukan pulau tidak menghasilkan laut teritorial apapun. Oleh karena itu, penting untuk mengetahui apa yang merupakan sebuah pulau. Sebuah pulau didefinisikan sebagai area tanah yang terbentuk secara alami, dikelilingi oleh air, yang berada di atas air pada ketinggian pasang surut, terdapat tiga syarat yaitu formasi harus alami dan bukan buatan; di atas permukaan laut dan terlihat di semua negara, lebih lanjut dalam air pasang. Namun, masalah dapat muncul, dan muncul dalam kasus di mana daerah yang terbentuk secara alami" kehilangan persyaratan "berada di atas air pada ketinggian pasang". Kemungkinan pergeseran dalam hal ini dari status pulau ke status 'non-daratan' mungkin merupakan hasil dari perubahan iklim yang terus meningkat keprihatinan global. "Dengan pemanasan global yang meningkat dan akibat kenaikan permukaan laut di seluruh dunia, mungkin atau bahkan kemungkinan suatu pulau dapat tenggelam di bawah air pasang untuk kehilangan status hukumnya sebagai pulau, lebih lanjut dalam David D. Caron \& Henry N. Scheiber, Bringing New Law to Ocean Waters, Publications on Ocean Development, 2004, hlm. 84.

18 Erin O'Donnell and Julia Talbot-Jones, 'Three Rivers Are Now Legally People - but That's Just the Start of Looking after Them', The Conversation, 2017. itu meliputi, inter alia, baik untuk Negara pantai atau Negara tidak berpantai:

(a) kebebasan berlayar;

(b) kebebasan penerbangan;

(c) kebebasan untuk memasang kabel dan pipa bawah laut, dengan tunduk pada Bab VI;

(d) kebebasan untuk membangun pulau buatan dan instalasi lainnya yang diperbolehkan berdasarkan hukum internasional, dengan tunduk pada Bab VI;

(e) kebebasan menangkap ikan, dengan tunduk pada persyaratan yang tercantum dalam bagian 2 ;

(f) kebebasan riset ilmiah, dengan tunduk pada Bab VI dan XIII. ${ }^{19}$

Kebebasan ini akan dilaksanakan oleh semua Negara, dengan memperhatikan sebagaimana mestinya kepentingan Negara lain dalam melaksanakan kebebasan laut lepas itu, dan juga dengan memperhatikan sebagaimana mestinya hak-hak dalam Konvensi ini yang bertalian dengan kegiatan di Kawasan. ${ }^{20}$

19 Julien Rochette and others, 'A New Chapter for the High Seas?', Issue Brief IDDRI Oceans and Coastal Zones, 2015.

20 Pasal 56 UNCLOS 1982 menetapkan hak, yurisdiksi dan kewajiban negara pantai, dimana dalam zona ekonomi eksklusif ada hak berdaulat berkaitan dengan negara pantai berkaitan dengan lainnya kegiatan untuk eksplorasi ekonomi dan eksploitasi zona seperti produksi energi dari air, arus dan angin. Penting diakui bahwa hukum membatasi deskripsi untuk "kegiatan" tanpa menghubungkan bentuk-bentuk terstruktur yang menyediakan fungsi "kegiatan" yang dijelaskan. Proyek-proyek yang akan segera dimulai beroperasi di laut yang meliputi pulau sumber daya alam, pulau bersumber cahaya, dan ladang angin. Sementara pulau buatan dan instalasi mungkin memiliki karakteristik yang berbeda. Struktur adalah istilah yang tampaknya sekali lagi mencakup segala sesuatu yang berkaitan dengan beragam sifat selain dari pulau buatan atau instalasi. Perbedaannya dibuat dalam ketentuan hanya dalam hal mendaftar pulau buatan sebagai 


\section{KESIMPULAN}

Status Pulau Sentinel bagian pulau alami yang tidak berpenghuni. Pemberian pulau alami dikarenakan pulau ini ada dan tidak merupakan pulau buatan dalam perspektif UNCLOS 1982. ${ }^{21}$ Sementara pemberian nama pulau tidak berpenghuninya karena adanya larangan dari Pemerintah India dengan argumen tidak menghuni untuk menjaga keberlangsungan hidup dari suku asli tersebut.

terpisah dari instalasi dan struktur. Kategori 'Pulau buatan' secara teori lebih besar dari 'instalasi lepas pantai' karena pulau buatan dibangun untuk tujuan apapun sedangkan instalasi dibangun hanya untuk tujuan mengeksplorasi dan mengeksploitasi, melestarikan dan mengelola sumber daya alam, baik yang hidup maupun yang tidak hidup, dari laut dan dasar laut dan lapisan bawahnya dan untuk tujuan ekonomi lainnya. UNCLOS 1982 memberdayakan negara untuk mengadopsi hukum dan peraturan untuk mencegah, mengurangi dan mengendalikan. Untuk menentukan sifat pulau buatan maka wajib merujuk pada definisi, penting status 'pulau alami' serta 'kapal', karena keduanya telah berasimilasi dengan pulau buatan, lebih lanjut dalam Francesca Galea, Artificial Islands In The Law of the Sea, Faculty of Laws University of Malta May 2009, hlm. 39-42.

Dalam kasus kepulauan, yang pulau-pulau penyusun dianggap membentuk keseluruhan dan lebar laut teritorial harus diukur dari pulau-pulau yang paling jauh dari pusat nusantara. Secara umum, konsep kepulauan hanya mengacu pada pengelompokan pulau, lebih lanjut dalam Fedelyn A. Santos, Beating The Deadline: Archipelagic State Compliance Under UNCLOS Article 47, World Maritime University, Sweden, 2008, hlm. 13.

Pemikiran demikian sebetulnya dalam mendefinisikan yaitu hambatan struktural teknologi dan ilmiah pembangunan berkelanjutan mengganggu negara berkembang, lebih lanjut dalam Iqbal, Imrana and Pierson, Charles (2017) "A North-South Struggle: Political and Economic Obstacles to Sustainable Development," Sustainable Development Law \& Policy: Vol. 16 : Iss. 2 , Article 4.

21 Untuk mendefinisikan pulau buatan menurut UNCLOS 1982 tidak bisa dilakukan karena adanya definisi yang tidak memenuhi unsur kebaruan saat ini. Pulau buatan saat ini cenderung mengarah pada pulau buatan yang dihuni oleh manusia, bukan pulau buatan untuk waktu tertentu saja.
Larangan yang diberikan Pemerintah India juga menjadikan sekitar Pulau Sentinel tidak bisa dijadikan sebagai garis pangkal menurut UNCLOS 1982 karena tidak hanya pulau tersebut yang menjadi objek larangan melainkan adanya jarak tertentu seperti yang dibas dalam pendahuluan. Pulau Sentinel dapat dijadikan sebagai usul pembuatan pulau tidak berpenghuni yang sifatnya alami sebagai bagian dari UNCLOS 1982. Larangann Pemerintah India dapat dijadikan pemikiran di Indonesia untuk mengelolah suatu pulau-pulau kecil tidak berpenghuni agar kelangsungan hidup hewan atau tumbuhan dapat berjalan dengan baik. Saran yang tepat dilakukan oleh India yaitu menjadikan Pulau Sentinel sebagai subjek hukum internasional seperti halnya Sungai Gangga. Hal ini menjadikan Pulau Sentinel sebagai pulau mandiri dan telah memenuhi sebagai subjek hukum internasional akrena kemampuan menjaga dirinya sendiri walaupun bentuk perlindungan sebenarnya berada dalam Pemerintah India. Subjek hukum tidak sama dengan hak asasi manusia, jadi "badan hukum" belum tentu harus menjadi manusia. Sebagai contohnya korporasi dianggap sebagai orang namun korporasi tersebut memiliki orang didalamnya. Memberikan status subjek hukum pada alam memberikan kemampuan untuk menuntut dan menggugat artinya dengan hal ini yang dipegang oleh Pemerintah India maka siapapun yang berusaha masuk ke Pulau Sentinel akan berhadapan dengan Pemerintah India. Diharapkan adanya sanksi akan tuntutan dari Pulau Sentinel melalui Pemerintah India akan memberi 
efek jera bagi siapapun untuk melakukan masuk paksa ke dalam Pulau Sentinel. ${ }^{22}$

\section{DAFTAR PUSTAKA}

Astra Yuli Satyarini Sukendar, Amanda Raissa, Tomy Michael, Pengurangan Pekerja Anak Perempuan Di Lingkungan Pondok Pesantren, Mizan: Jurnal Ilmu Hukum, Volume 8 Nomor 2, Desember 2019 ISSN: 2301-7295 e-ISSN: 2657-2494.

Beckman, R. C. and Schofield, C. H. (2014). Defining EEZ claims from islands: A potential South China Sea change. International Journal of Marine and Coastal Law, 29 (2), 193-243.

David D. Caron \& Henry N. Scheiber, Bringing New Law to Ocean Waters, Publications on Ocean Development, 2004.

Fedelyn A. Santos, Beating The Deadline: Archipelagic State Compliance Under UNCLOS Article 47, World Maritime University, Sweden, 2008.

FISHERIES CASE (United Kingdom v. Norway) International Court of Justice December 18, 1951 General List No. 5.

Francesca Galea, Artificial Islands in The Law of the Sea, Faculty of Laws University of Malta May 2009.

Hutchison, Abigail, 'The Whanganui River as a Legal Person', Alternative Law Journal, 2014

$<$ https://doi.org/10.1177/1037969X1 403900309>

I Wayan Kartika, Hukum Laut Internasional Dan Hukum Laut Indonesia, Yrama Widya, Bandung, 2014.

Iqbal, Imrana and Pierson, Charles (2017) "A North-South Struggle: Political and Economic Obstacles to Sustainable Development,"

22 Abigail Hutchison, 'The Whanganui River as a Legal Person', Alternative Law Journal, 2014 <https://doi.org/10.1177/1037969X1403900309>.
Sustainable Development Law \& Policy: Vol. 16: Iss. 2, Article 4.

Jyoti Dwivedi, The Dependence of Andaman and Nicobar Island Tribal Communities on Herbal Remedies, IOSR Journal of Environmental Science, Toxicology and Food Technology (IOSR-JESTFT) e-ISSN: 2319-2402, $\quad p-I S S N$ : 23192399. Volume 9, Issue $11 \mathrm{Ver}$. II (Nov. 2015), PP 45-53.

Levy, J. K., P. C. Crawford, M. R. Lappin, E. J. Dubovi, M. G. Levy, R. Alleman, and others, 'Infectious Diseases of Dogs and Cats on Isabela Island, Galapagos', Journal of Veterinary Internal Medicine, 2008<https://doi.org/10.1111/j.19391676.2007.0034.x>

Lister, Natasha, and Ema Muk-Pavic, 'Sustainable Artificial Island Concept for the Republic of Kiribati', Ocean Engineering, 2015 $<$ https://doi.org/10.1016/j.oceaneng. 2015.01.013>

Malcolm N. Shaw QC, International Law Sixth Edition, Cambridge University Press, The Edinburgh Building, Cambridge CB2 8RU, UK, 2008.

Mazen Adi, The Application of The Law of The Sea and The Convention on The Mediterranean Sea, United Nations-Nippon Foundation Fellow 2008 - 2009, Division for Ocean Affairs And The Law Of The Sea Office Of Legal Affairs, The United Nations New York, 2009.

Michael, Tomy, 'RIGHT TO HAVE RIGHTS', Mimbar Keadilan, 2017, $106<$ https://doi.org/10.30996/mk.v0i $0.2203>$

Minarti Harahap, Irma, Achmad Fahrudin, and Yusli Wardiatno, 'Pengelolaan Kolaboratif Kawasan Konservasi Penyu Pangumbahan Kabupaten Sukabumi (Collaborative Management of Sea Turtle Pangumbahan Marine Protected Area, Sukabumi District)', Jurnal 
Ilmu Pertanian Indonesia (JIPI), 2015

Novianto, Rizal Dwi, Dimas Agung Firmansyah, and Naufal Adi Pratama, 'PENYELESAIAN SENGKETA DI LAUT NATUNA UTARA', Jurnal Hukum Bisnis Bonum Commune, 2020 $<$ https://doi.org/10.30996/jhbbc.v3i1 $.3074>$

O'Donnell, Erin, and Julia Talbot-Jones, 'Three Rivers Are Now Legally People - but That's Just the Start of Looking after Them', The Conversation, 2017

Prasenja, Yanelis, 'Peran Masyarakat Dalam Pengelolaan Ekominawisata Pulau Lusi, Kabupaten Sidoarjo', Majalah Geografi Indonesia, 2018 $<$ https://doi.org/10.22146/mgi.2869>

Press Information Bureau Government of India Ministry of Home Affairs, 5 Feb 2019 ,
https://pib.gov.in/Pressreleaseshare.a spx?PRID $=1562728, \quad$ diakses 6 Februari 2020.

Rochette, Julien, Glen Wright Iddri, Kristina M Gjerde Iucn, Thomas Greiber, Sebastian Unger Iass, and Aurélie Spadone Iucn, 'A New Chapter for the High Seas?', Issue Brief IDDRI Oceans and Coastal Zones, 2015

Sondakh, Bernard Kent, 'PERAN TNI AL DALAM PENGAMANAN DAN PEMBERDAYAAN PULAU TERLUAR RI', Jurnal Hukum \& Pembangunan, 2017 $<$ https://doi.org/10.21143/jhp.vol33. no1.1368>

Wuryandari, Ganewati, and Sandy Nur Ikfal Raharjo, 'Menegosiasikan Batas Wilayah Maritim Indonesia Dalam Bingkai Negara Kepulauan', Masyarakat Indonesia, 2016 